\title{
A Review on Detonation Gun Sprayed Coatings
}

\author{
Lakhwinder Singh $^{1^{*}}$, Vikas Chawla ${ }^{2}$, J.S. Grewal ${ }^{1}$ \\ ${ }^{1}$ Department of mechanical engineering, G.N.D.E.C. Ludhiana, Punjab, India \\ ${ }^{2}$ Department of mechanical engineering, B.M.S.C.E Muktsar-152026, Punjab, India \\ *Corresponding author: tacto9@yahoo.com
}

\begin{abstract}
Materials are precious resources. Different methods are employed to protect the material from degradation. Thermal spraying is one of the most effective method to protect the material from wear, high temperature corrosion, stresses and erosion, thus increasing the life of material in use. Detonation gun spraying is one of the thermal spraying techniques known for providing hard, wear resistant and dense microstructured coatings. This paper summarizes the results of previous research done by various authors on different coatings done by detonation gun spraying technique.
\end{abstract}

Keywords: thermal spraying, detonation gun

\section{INTRODUCTION}

Thermal spraying is an effective and low cost method to apply thick coatings to change surface properties of the component. Coatings are used in a wide range of applications including automotive systems, boiler components, and power generation equipment, chemical process equipment, aircraft engines, pulp and paper processing equipment, bridges, rollers and concrete reinforcements, orthopedics and dental, land-based and marine turbines, ships [1]. Among the commercially available thermal spray coating techniques, Detonation Spray (DS) and High Velocity Oxy Fuel (HVOF) spray are the best choices to get hard, dense and wear resistant coatings as desired [3]. The objective of the work is to analyze the role of detonation gun spray coating to enhance the properties of surface of substrate to counter the problems like erosion, residual stress, fretting fatigue, thermal behavior and corrosion etc. 


\section{THERMAL SPRAYING}

Thermal spraying has emerged as an important tool of increasingly sophisticated surface engineering technology. The different functions of the coating, such as wear and corrosion resistance, thermal or electrical insulation can be achieved using different coating techniques and coating materials [2]. Thermal spraying is the application of a material (the consumable) to a substrate by melting the material into droplets and impinging the softened or molten droplets on a substrate to form a continuous coating. There are many thermal spray coating deposition techniques available, and choosing the best process depends on the functional requirements, adaptability of the coating material to the technique intended, level of adhesion required, (size, shape, and metallurgy of the substrate), and availability and cost of the equipment.[1] Thermal spray processes that have been considered to deposit the coatings are enlisted below:

(1) Flame spraying with a powder or wire, (2) Electric arc wire spraying, (3) Plasma spraying, (4) Spray and fuse, (5) High Velocity Oxy-fuel (HVOF) spraying, (6) Detonation Gun.

\section{DETONATION GUN SPRAYING}

D-gun spray process is a thermal spray coating process, which gives an extremely good adhesive strength, low porosity and coating surface with compressive residual stresses [4]. A precisely measured quantity of the combustion mixture consisting of oxygen and acetylene is fed through a tubular barrel closed at one end. In order to prevent the possible back firing a blanket of nitrogen gas is allowed to cover the gas inlets. Simultaneously, a predetermined quantity of the coating powder is fed into the combustion chamber. The gas mixture inside the chamber is ignited by a simple spark plug. The combustion of the gas mixture generates high pressure shock waves (detonation wave), which then propagate through the gas stream. Depending upon the ratio of the combustion gases, the temperature of the hot gas stream can go up to $4000 \mathrm{deg} \mathrm{C}$ and the velocity of the shock wave can reach $3500 \mathrm{~m} / \mathrm{sec}$. The hot gases generated in the detonation chamber travel down the barrel at a high velocity and in the process heat the particles to a plasticizing stage (only skin melting of particle) and also accelerate the particles to a velocity of $1200 \mathrm{~m} / \mathrm{sec}$. These particles then come out of the barrel and impact the component held by the manipulator to form a coating. The high kinetic energy of the hot powder particles on impact with the substrate result in a build up of a very dense and strong coating. The coating thickness developed on the work piece per shot depends on the ratio of combustion gases, powder particle size, carrier gas flow rate, frequency and distance between the barrel end and the substrate. Depending on the required coating thickness and the type of coating material the detonation spraying cycle can be repeated at the rate of 1-10 shots per second. The chamber is finally flushed with nitrogen again to remove all the remaining "hot" powder particles from the chamber as these can otherwise detonate the explosive mixture in an irregular fashion and render the whole process uncontrollable. With this, one detonation cycle is completed above procedure is repeated at a particular frequency until the required thickness of coating is deposited. 


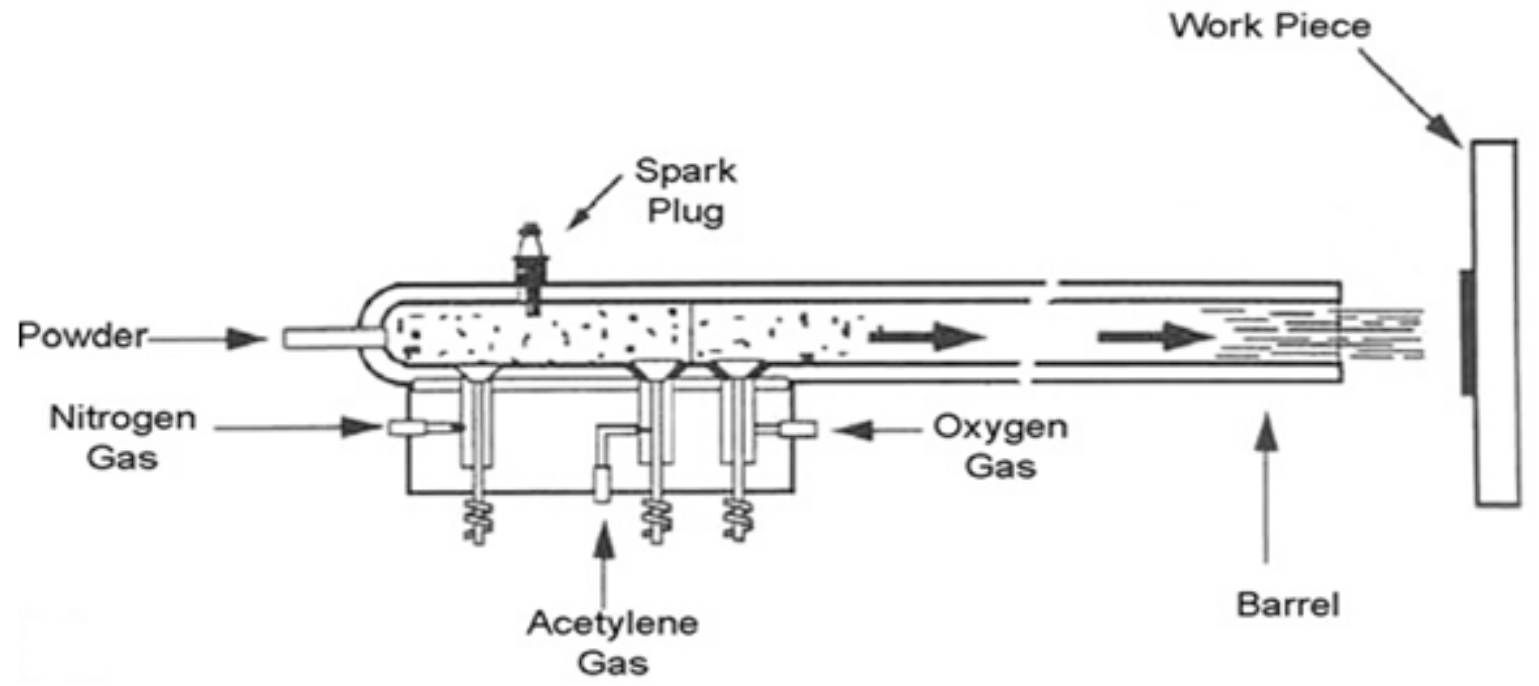

Fig.1. Detonation Gun process [5]

The chamber is finally flushed with nitrogen again to remove all the remaining "hot" powder particles from the chamber as these can otherwise detonate the explosive mixture in an irregular fashion and render the whole process uncontrollable. With this, one detonation cycle is completed above procedure is repeated at a particular frequency until the required thickness of coating is deposited [3].

\section{STUDIES RELATED TO DETONATION GUN SPRAYED COATINGS}

Sova et al. [6] studied the development of multimaterial coatings by cold spray and gas detonation spraying. The basic objective was the development of multifunctional multimaterial protective coatings using cold spraying (CS) and computer controlled detonation spraying (CCDS).As far as CS was concerned, the separate injection of each powder into different zones of the carrier gas stream was applied. $\mathrm{Cu}-\mathrm{Al}, \mathrm{Cu}-\mathrm{SiC}, \mathrm{Al}-\mathrm{Al}_{2} \mathrm{O}_{3}, \mathrm{Cu}-\mathrm{Al}_{2} \mathrm{O}_{3}, \mathrm{Al}-\mathrm{SiC}, \mathrm{Al}-\mathrm{Ti}$ and Ti-SiC coatings were successfully sprayed. As to CCDS, powders were sprayed with a recently developed apparatus that was characterized by a high-precision gas supply system and a finedosed twin powder feeding system. Computer control provided a flexible programmed readjustment of the detonation gases energy impact on powder thus allowing selecting the optimal for each component spraying parameters to form composite and multilayered coatings. Several powders were sprayed to obtain composite coatings, specifically, among others, WC$\mathrm{Co}-\mathrm{Cr}+\mathrm{Al}_{2} \mathrm{O}_{3}, \mathrm{Cu}+\mathrm{Al}_{2} \mathrm{O}_{3}$, and $\mathrm{Al}_{2} \mathrm{O}_{3}+\mathrm{ZrO}_{2}$.

Estimation of residual stress and its effects on the mechanical properties of detonation gun sprayed WC-Co coatings was done by Wang et al. [7]. Thick coatings seriously affect coatings performance during their service. Authors gave importance to understand the mechanisms by which the stresses arise, to predict and control the stresses for improving coating properties. 
Because the Stoney formula is commonly used to relate stress to curvature for thin coatings, a new calculation formula was developed to estimate the residual stresses of thick coatings that represent a comprehensive stress state of the coated specimen. Based on the deduced formula and accurate curvature measurements, the residual stresses of detonation gun (D-Gun) sprayed WC-Co coatings with different thickness were obtained. With increasing the coating thickness, the residual stress changed gradually from the tensile nature to a compressive nature. Meanwhile, the coating was in an approximately stress-free state at the thickness of around $365 \mu \mathrm{m}$. The analysis results emphasized the significance of peening stress in controlling the final stress state of the coated specimen, due to the high spraying velocity and kinetic energy during the D-Gun spraying process. Finally, the effects of residual stress on the mechanical properties of the coating were understood, namely, the compressive stress could significantly improve the coating properties, whereas the tensile stress impaired the coating properties.

Sundararajan et al. [8] evaluated the tribological performance of $200 \mu \mathrm{m}$ thick TiMo(CN)-28Co and TiMo(CN)-36NiCo coatings obtained by using the detonation spray coating system. Towards the above purpose, the detonation spray coating conditions were optimized to obtain the best coating properties (low porosity, high wear resistance) by varying two of the important coating process variables, i.e., oxygen to fuel ratio and gas volume. In both the coatings it was observed that the best tribological performance and also the lowest porosity were obtained. However, the coatings with the highest hardness did not exhibit the best tribological performance. A comparison of the tribological performance of the optimized TiMo(CN) type coatings with that of optimized WC-Co coatings revealed that the abrasion resistance of TiMo(CN) type coatings is comparable to that of WC-Co coatings. However, the erosion and sliding wear resistance of TiMo(CN) type coatings were considerably lower than that of WC-Co coatings.

Kamal et al. [9] investigated the microstructure and mechanical properties of detonation gun sprayed NiCrAlY $+\mathrm{CeO}_{2}$ alloy coatings deposited on superalloys. The morphologies of the coatings were characterized by using the techniques such as optical microscopy, X-ray diffraction and field emission scanning electron microscopy/energy-dispersive analysis. The coating depicted the formation of dendritic structure and the microstructural refinement in the coating was due to ceria. Average porosity on three substrates was less than $0.58 \%$ and surface roughness of the coatings was in the range of $6.17-6.94 \mu \mathrm{m}$. Average bond strength and microhardness of the coatings were found to be $58 \mathrm{MPa}$ and 697-920Hv, respectively.

Microstructure characterization of D-gun sprayed $\mathrm{Fe}-\mathrm{Al}$ intermetallic coatings was done by Senderowski et al. [10]. Intermetallic Fe-Al type coatings about $100 \mu \mathrm{m}$ thick were deposited on a plain carbon steel substrate by D-gun spraying technique. The 40-75 $\mu \mathrm{m}$ size fraction of the feedstock powder was obtained by self-propagating high-temperature synthesis and sieved prior to D-gun spraying. This powder contained a mixture of $\mathrm{Fe}-\mathrm{Al}$ type intermetallic phases 
conventionally appointed $\mathrm{Fe}_{x} \mathrm{Al}_{y}$. The $\mathrm{Fe}-\mathrm{Al}$ coatings were analysed by transmission electron microscopy, selected area electron diffraction, and semi-quantitative energy-dispersive X-ray analysis in micro-areas. Particular attention was paid to the substructure of the individual grains in the coating zone abutting the steel substrate. The Fe-Al coatings have a multi-layer composite structure. The results explain the formation mechanism of the coating microstructure. The powder particles, which were heterogeneous in chemical composition and structure, were heated, highly softened or even partially melted and oxidised while flying from the gun barrel to the substrate. After impacting the substrate or previously deposited material and being shot peened by the following powder particles, they were rapidly cooled and plastically deformed, creating overlapping splats. In the zone adjacent to the substrate, alternating $\mathrm{FeAl}$ and $\mathrm{Fe}_{2} \mathrm{Al}_{5}$ intermetallic phases formed columnar crystals. The columnar crystal areas were separated by elongated amorphous oxide layers. Areas of mixed equiaxed subgrains of $\mathrm{FeAl}$ and $\mathrm{Fe}_{3} \mathrm{Al}$ phases, fine grains of Fe-rich $\mathrm{Fe}(\mathrm{Al})$ solid solution, and micro- and nano-pores were also present.

Wang et al. [11] designed the separation device for detonation gun spraying system and studied its effects on the performance of WC-Co coatings. The WC-Co coatings were synthesized by the D-gun spraying system with and without using a separation device, respectively. The results showed that the use of the separation device resulted in better properties of the D-gun sprayed WC-Co coatings, e.g., lower the surface roughness, lower the porosity, higher the microhardness, higher the elastic modulus, and higher the interfacial adhesive strength. Also, the tribological performance of the WC-Co coatings was improved. The relationship of surface roughness, microhardness, elastic modulus, adhesive strength, and wear resistance of the WCCo coatings with porosity was discussed. At the same time, there is an inevitable disadvantage for using the separation device, i.e., the relatively lower effective utility rate of the feedstock powder. Therefore, the separation device is suitable to be applied in occasions of highperformance requirements where increased costs are acceptable.

Formation and corrosion behavior of Fe-based amorphous metallic coatings prepared by detonation gun spraying was studied by ZHOU et al. [12]. Amorphous metallic coatings with a composition of $\mathrm{Fe}_{48} \mathrm{Cr}_{15} \mathrm{Mo}_{14} \mathrm{C}_{15} \mathrm{~B}_{6} \mathrm{Y}_{2}$ were prepared by detonation gun spraying process. Microstructural studies show that the coatings present a densely layered structure typical of thermally sprayed deposits with the porosity below 2\%. Both crystallization and oxidation occurred obviously during spraying process, so that the amorphous fraction of the coatings decreased to 54\% compared with fully amorphous alloy ribbons of the same component. Corrosion behavior of the amorphous coatings was investigated by electrochemical measurement. The results show that the coatings exhibit extremely wide passive region and low passive current density in 3.5\% $\mathrm{NaCl}$ (mass fraction) and $1 \mathrm{~mol} / \mathrm{L} \mathrm{HCl}$ solutions, which illustrates excellent ability to resist localized corrosion. 
Rajasekaran et al. [13] evaluated the effect of grinding on plain fatigue and fretting fatigue behaviour of detonation gun sprayed $\mathrm{Cu}-\mathrm{Ni}-\mathrm{In}$ coating on $\mathrm{Al}-\mathrm{Mg}-\mathrm{Si}$ alloy. Uniaxial plain fatigue and fretting fatigue tests were carried out on detonation gun sprayed $\mathrm{Cu}-\mathrm{Ni}$-In coating on $\mathrm{Al}-\mathrm{Mg}-\mathrm{Si}$ alloy samples. The samples in three conditions were considered: uncoated, as-coated and ground after coating. Ground coated specimens exhibited superior plain fatigue and fretting fatigue lives compared with uncoated and as-coated specimens. The life enhancement has been discussed in terms of surface finish and and residual compressive stresses at the surface.

The cyclic oxidation behavior of detonation-gun-sprayed $\mathrm{Cr}_{3} \mathrm{C}_{2}-\mathrm{NiCr}$ coating on three different superalloys namely Superni 75, Superni 718 and Superfer $800 \mathrm{H}$ at $900{ }^{\circ} \mathrm{C}$ for 100 cycles in air under cyclic heating and cooling conditions has been investigated by kamal et al. [14]. The kinetics of oxidation of coated and bare superalloys was analysed, using thermogravimetric technique. It was observed that all the coated and bare superalloys obey a parabolic rate law of oxidation. X-ray diffraction, FE-SEM/EDAX and X-ray mapping techniques were used to analyse the oxidation products of coated and bare superalloys. The results on the $\mathrm{Cr}_{3} \mathrm{C}_{2}-\mathrm{NiCr}-$ coated superalloys showed better oxidation resistance due to the formation of a compact and adhesive thin $\mathrm{Cr}_{2} \mathrm{O}_{3}$ scale on the surface of the coating during oxidation. The scale remained intact and adherent to the partially oxidised coating during cyclic oxidation due to its good compatibility and similar thermal expansion coefficient between $\mathrm{Cr}_{3} \mathrm{C}_{2}-\mathrm{NiCr}$ coating and the superalloy substrates. In all the coated superalloys, the chromium, iron, silicon and titanium were oxidised in the inter-splat region, whereas splats which consisted mainly of $\mathrm{Ni}$ remained unoxidised. The parabolic rate constants of $\mathrm{Cr}_{3} \mathrm{C}_{2}-\mathrm{NiCr}$-coated alloys were lower than that of the bare superalloys.

Kamal et al. [15] evaluated the cyclic hot corrosion behaviour of detonation gun sprayed $\mathrm{Cr}_{3} \mathrm{C}_{2}-$ $25 \% \mathrm{NiCr}$ coatings on nickel- and iron-based superalloys $\mathrm{Cr}_{3} \mathrm{C}_{2}-\mathrm{NiCr}$ cermet coatings were deposited on two Ni-based superalloys, namely superni 75, superni 718 and one Fe-based superalloy superfer $800 \mathrm{H}$ by detonation-gun thermal spray process. The cyclic hot-corrosion studies were conducted on uncoated as well as D-gun coated superalloys in the presence of mixture of 75 wt. $\% \mathrm{Na}_{2} \mathrm{SO}_{4}+25$ wt. $\% \mathrm{~K}_{2} \mathrm{SO}_{4}$ film at $900{ }^{\circ} \mathrm{C}$ for 100 cycles. Thermogravimetric technique was used to establish the kinetics of hot corrosion of uncoated and coated superalloys. X-ray diffraction, FE-SEM/EDAX and X-ray mapping techniques were used to analyze the corrosion products for rendering an insight into the corrosion mechanisms. It was observed that $\mathrm{Cr}_{3} \mathrm{C}_{2}-\mathrm{NiCr}$-coated superalloys showed better hot-corrosion resistance than the uncoated superalloys in the presence of $75 \mathrm{wt}$ \% $\mathrm{Na}_{2} \mathrm{SO}_{4}+25 \mathrm{wt} \% \mathrm{~K}_{2} \mathrm{SO}_{4}$ film as a result of the formation of continuous and protective oxides of chromium, nickel and their spinel, as evident from the XRD analysis.

Zhu et al. [16] studied the microstructure of TiC-Fe36Ni composite coatings by detonation-gun spraying. A kind of Ti-Fe-Ni-C compound powder was prepared by a novel precursor pyrolysis 
process using ferro-titanium, carbonyl nickel powder and sucrose as raw materials. The powder had a very compact structure and was uniform in particle size. The TiC-Fe36Ni composite coatings were simultaneously in-situ synthesized by Reactive Detonation-gun Spraying (RDS) using these Ti-Fe-Ni-C compound powders. The coatings presented typical morphology of thermal spraying coatings with two different areas: one was the area of $\mathrm{TiC}$ distribution where the round fine TiC particles (from 300nm to $1 \mu \mathrm{m}$ ) were dispersed in the Fe36Ni alloy matrix; the other was the area of $\mathrm{TiC}$ accumulation (from 2 to $4 \mu \mathrm{m}$ ). The surface hardness of the composite coating reached about $94 \pm 2(\mathrm{HR} 15 \mathrm{~N})$.

Senderowski et al. [17] studied the Gas detonation spray forming of $\mathrm{Fe}-\mathrm{Al}$ coatings in the presence of interlayer. The gas detonation sprayed (GDS) NiAl and NiCr intermediate layers underneath of the intermetallic Fe-Al type coatings on plain carbon steel substrate form bilayer coating system interacting with external environment and/or metal elements. The interface layers are responsible for hardness, bond strength, thermal stability and adhesive strength of the whole GDS structure. The physical-chemical properties of the intermediate layers, combined with unique, very dense and pore free intermetallic $\mathrm{Fe}-\mathrm{Al}$ coating obtained from self-decomposing powders resulted in new, beneficial features of the whole GDS structure which became more complex, enabled independent control of its functional properties and considerably reduced negative gradients of stress and temperature influencing the substrate and increasing adhesion strength. The achievement of homogenous and refined structure (comprising of small $(<1 \mu \mathrm{m})$ and equiaxed sized grains) creates a thermal barrier based on high-melting point intermetallic phases containing $\mathrm{Al}_{2} \mathrm{O}_{3}$ ceramics which is responsible for properties of the GDS bilayer coatings. The application properties were investigated and the specific multilayer structure of the GDS coating was analyzed such as the phase composition, the degree of order, grain morphology, the quality of substrate/interlayer/external coating bonds, and first of all the influence of hardness of the $\mathrm{NiAl}$ or $\mathrm{NiCr}$ intermediate layers on the hardness and thermal stability of the $\mathrm{FeAl}$ coating after gas detonation spraying and additional heating at $750{ }^{\circ} \mathrm{C}$ and $950{ }^{\circ} \mathrm{C}$ for $10 \mathrm{~h}$.

Performance of plasma sprayed and detonation gun sprayed $\mathrm{Cu}-\mathrm{Ni}-\mathrm{In}$ coatings on $\mathrm{Ti}-6 \mathrm{Al}-4 \mathrm{~V}$ under plain fatigue and fretting fatigue loading was evaluated by Rajasekaran et al. [18]. Cu-NiIn powder was coated on $\mathrm{Ti}-6 \mathrm{Al}-4 \mathrm{~V}$ fatigue test samples using plasma spray and detonation gun (D-gun) spray processes. Coatings were characterized in terms of microstructure, porosity, microhardness, residual stresses and surface roughness. Uniaxial plain fatigue and fretting tests were carried out at room temperature on uncoated and coated specimens. D-gun sprayed coating was dense with lower porosity compared with the plasma sprayed coating. D-gun sprayed coating was harder than the plasma sprayed coating and substrate because of its higher density and cohesive strength. Surfaces were very rough in both the coatings. While D-gun sprayed coating surface had higher compressive residual stresses, plasma sprayed coating surface exhibited lower values of compressive residual stresses and even tensile residual stresses. The ill 
effect of surface roughness was overcome by the beneficial influence of higher compressive residual stresses on the surface and higher surface hardness and so the D-gun sprayed samples exhibited superior plain fatigue lives compared with uncoated specimens. Though the plasma sprayed samples had relatively lower hardness, higher surface roughness and almost similar values of residual stresses on the surface compared with the uncoated specimens, they exhibited longer plain fatigue lives. This may be attributed to the layered structure of the coating. Though D-gun sprayed samples experienced higher friction forces, they exhibited superior fretting fatigue lives due to the presence of higher compressive residual stresses, higher surface hardness and higher surface roughness compared with uncoated specimens. The very rough surface of plasma sprayed samples enhanced their fretting fatigue lives compared with the uncoated samples. Higher surface hardness and higher compressive residual stress of the D-gun sprayed specimens were responsible for their superior fretting fatigue lives compared with the plasma sprayed specimens.

Yuan et al. [19] investigated the Oxidation behavior of thermal barrier coatings with HVOF and detonation-sprayed NiCrAlY bondcoats. The high-velocity oxygen-fuel (HVOF) technology was employed to deposit the bondcoat of a thermal barrier coating (TBC) system. The isothermal oxidation rate at $1100^{\circ} \mathrm{C}$ of the TBC system with the HVOF bondcoat is two times lower than that of the TBC system with the detonation-sprayed bondcoat. The better isothermal oxidation resistance of the TBCs with HVOF sprayed bondcoats demonstrates that unlike alumina dispersoids in the HVOF sprayed bondcoat, rough surface of the detonation-sprayed bondcoat is undesirable for the detonation-sprayed TBC system concerning oxidation due to a large specific surface area and unfavorable oxides on the bondcoat.

The influence of detonation gun sprayed alumina coating on Al-Mg-Si alloy (AA 6063) test samples subjected to cyclic loading with and without fretting was studied by Rajasekaran et al.[20]. Coated samples were grounded to have coatings of two different thickness values, 40 and $100 \mu \mathrm{m}$. Both 40- and 100- $\mu \mathrm{m}$-thick coated specimens experienced almost the same but slightly higher friction force compared with uncoated samples. Under plain fatigue loading, $100 \mu \mathrm{m}$ coated specimens exhibited inferior lives due to the presence of lower surface compressive residual stress compared with uncoated and 40- $\mu$ m-thick coated samples. Under fretting fatigue loading, uncoated specimens exhibited inferior lives compared with coated samples owing to the very low hardness of the uncoated specimens (80 against $1020 \mathrm{HV}_{0.2}$ ). The reason for the superior fretting fatigue lives of 40 - $\mu \mathrm{m}$-thick coated samples compared with 100 - $\mu \mathrm{m}$-thick coated samples was the presence of relatively higher surface compressive residual stress in 40$\mu \mathrm{m}$-thick coated specimens.

Hot corrosion behavior of detonation gun sprayed $\mathrm{Cr}_{3} \mathrm{C}_{2}-\mathrm{NiCr}$ coatings on $\mathrm{Ni}$ and Fe-based super alloys in $\mathrm{Na}_{2} \mathrm{SO}_{4}-60 \% \mathrm{~V}_{2} \mathrm{O}_{5}$ environment at $900^{\circ} \mathrm{C}$ was investigated by Kamal et al.[21]. The deposited coatings on these superalloy substrates exhibit nearly uniform, adherent and dense 
microstructure with porosity less than $0.8 \%$. Thermogravimetry technique was used by authors to study the high temperature hot corrosion behavior of bare and $\mathrm{Cr}_{3} \mathrm{C}_{2}-\mathrm{NiCr}$ coated superalloys in molten salt environment $\left(\mathrm{Na}_{2} \mathrm{SO}_{4}-60 \% \mathrm{~V}_{2} \mathrm{O}_{5}\right)$ at high temperature $900{ }^{\circ} \mathrm{C}$ for 100 cycles. The corrosion products of the detonation gun sprayed $\mathrm{Cr}_{3} \mathrm{C}_{2}-\mathrm{NiCr}$ coatings on superalloys were analyzed by using XRD, SEM, and FE-SEM/EDAX to reveal their microstructural and compositional features for elucidating the corrosion mechanisms. It is shown that $\mathrm{the} \mathrm{Cr}_{3} \mathrm{C}_{2}-$ $\mathrm{NiCr}$ coatings on $\mathrm{Ni}$ - and Fe-based superalloy substrates are found to be very effective in decreasing the corrosion rate in the given molten salt environment at $900{ }^{\circ} \mathrm{C}$. Particularly, the coating deposited on Superfer $800 \mathrm{H}$ showed a better hot corrosion protection as compared to Superni 75 and Superni 718. The coatings serve as an effective diffusion barrier to preclude the diffusion of oxygen from the environment into the substrate superalloys. It is concluded that the hot corrosion resistance of the D-gun sprayed $\mathrm{Cr}_{3} \mathrm{C}_{2}-\mathrm{NiCr}$ coating is due to the formation of desirable microstructural features such as very low porosity, uniform fine grains, and the flat splat structures in the coating.

Babu et al. [22] demonstrated how the microstructure evolution in terms of nature/extent of decomposition of WC as well as properties of WC-12wt.\% Co coatings is critically dependent on variation of oxygen-fuel (OF) ratio. The coating deposition was carried out over a wide range of OF ratios using a detonation spray technique, and particle velocity was measured using a highspeed particle diagnostics system. The presence of free $\mathrm{W}$ and increased $\mathrm{W}_{2} \mathrm{C}$ phase was observed under deposition at higher OF ratios of 1.5 or 2.0, and this was confirmed using XRD, EBSD and SEM-EDS elemental mapping. In order to obtain representative hardness and modulus of the as-deposited coatings, careful measurements and analysis of indentation response (cross-section and surface) were carried out using nanoindentation and Vickers hardness testers. Based on experimental results, a major emphasis has been put forward to establish a processingstructure-property correlation for detonation sprayed WC-12Co coatings.

Park et al. [23] studied the mechanical properties and microstructure evolution of the nano WCCo coatings fabricated by detonation gun spraying with post heat treatment. The thermal behavior of WC particles in the coatings was also investigated. WC-Co coatings containing nano carbide particles in the $100-200 \mathrm{~nm}$ range were fabricated by detonation gun spraying. Considerable phase decomposition of $\mathrm{WC}$ to $\mathrm{W}_{2} \mathrm{C}$ and amorphous phase was detected, which degrades the mechanical properties of coatings. In order to improve the mechanical properties of the coatings by recovery of dissociated carbide phases, post heat treatment was conducted in an Ar environment in the temperature range of $400-900{ }^{\circ} \mathrm{C}$. Microhardness and fracture toughness were measured by Vickers indentation testing and wear resistance was also evaluated by using a scratch tester. Phase evolution and microstructural changes due to post heat treatment were investigated by optical microscopy, X-ray diffractometry and field-emission scanning electron microscopy. After heat treatment in all temperature ranges, microhardness increased. Fracture toughness and wear resistance of coatings were increased by increasing temperature to $800{ }^{\circ} \mathrm{C}$ 
but decreased after heat treatment at $900{ }^{\circ} \mathrm{C}$. Amorphous phase disappeared and other carbide phases such as $\mathrm{W}_{3} \mathrm{Co}_{3} \mathrm{C}$ and $\mathrm{W}_{6} \mathrm{Co}_{6} \mathrm{C}$ formed during heat treatment above $700{ }^{\circ} \mathrm{C}$.

Structure, mechanical and sliding wear properties of $\mathrm{WC}-\mathrm{Co} / \mathrm{MoS}_{2}-\mathrm{Ni}$ coatings by detonation gun spray were investigated by Du et al. [24]. A series of $\mathrm{WC}-\mathrm{Co} / \mathrm{MoS}_{2}-\mathrm{Ni}$ coatings were deposited by detonation gun (D-gun) spray, using a commercial WC-Co powder and a $\mathrm{MoS}_{2}-\mathrm{Ni}$ powder, with a proper spray condition in view of both powders. The structures, mechanical and sliding wear properties of these coatings were characterized. The results by SEM, EMPA, XRD and XRF indicate that the $\mathrm{MoS}_{2}$ composition was kept and distributed homogeneously in the $\mathrm{WC}-\mathrm{Co} / \mathrm{MoS}_{2}-\mathrm{Ni}$ coatings with its content little higher than the feed powder. The results also indicated that hardness, fracture toughness and adhesion of the $\mathrm{WC}-\mathrm{Co} / \mathrm{MoS}_{2}-\mathrm{Ni}$ coatings decrease with the increasing $\mathrm{MoS}_{2}$ content in the coating, while porosity and roughness the same, comparing with a pure WC-Co coating deposited under the same condition. Authors found that this $\mathrm{WC}-\mathrm{Co} / \mathrm{MoS}_{2}-\mathrm{Ni}$ coating possesses self-lubricating property. Furthermore, the $\mathrm{MoS}_{2}$ composition in the $\mathrm{WC}-\mathrm{Co} / \mathrm{MoS}_{2}-\mathrm{Ni}$ coatings shows a contribution in lowering wear rate under dry sliding conditions when its content is lower than $4.9 \mathrm{wt}$ \%. However, the wear rate was higher when the content is $7.2 \mathrm{wt} . \%$, which indicate that the $\mathrm{MoS}_{2}$ content should be proper for an improvement of the D-gun sprayed $\mathrm{WC}-\mathrm{Co} / \mathrm{MoS}_{2}-\mathrm{Ni}$ coating on wear resistance.

Microstructure dependent erosion in $\mathrm{Cr}_{3} \mathrm{C}_{2}-20(\mathrm{NiCr})$ coating deposited by a detonation gun was analyzed by Murthy et al. [25]. The coated samples were heat-treated at $600{ }^{\circ} \mathrm{C}$ for $11 / 2 \mathrm{~h}$ and allowed to cool in air. A systematic microstructural study was carried out using SEM and TEM to understand the microstructural changes. The mechanical properties like hardness, indentation fracture toughness and adhesion strength of the coating in the as-sprayed and heat-treated conditions were also determined. The change in solid particle erosion of the coating was correlated with the microstructural and subsequent mechanical property changes. It was observed that exposure of the as-sprayed coating to elevated temperature improves the wear resistance. Authors concluded that crystallisation of the amorphous phase into nanocrystalline composite combined with better bonding between the adjacent splats through sintering contributes to improved hardness, fracture toughness and wear resistance of the heat-treated coating. The deformation characteristics of the binder phase, amorphous vis-à-vis crystalline, also influence the wear behaviour of the coating.

A study on phase stability of as sprayed Alumina-13 wt.\% Titania coatings grown by detonation gun and plasma spraying on low alloy steel substrates was observed by Venkataraman et al. [26]. AT-13 wt.\% type powders, depending on the process used for spraying has shown variable type of resultant phases in the as sprayed conditions. In a detonation gun process it appeared that freezing of the molten plume with the same composition as the liquid was possible, in contrast to this in a typical plasma spraying process preferential evaporation and phase separation of the solute from the molten plume was prevalent. These variations to the solidification paths has 
resulted in a totally metastable $\gamma$ phase in the former process and in the latter process heterogeneous nucleation of $\alpha$ phase in addition to the normal nucleation of metastable $\gamma$ phase was observed. In all cases the titanium present in the solute appears to be merely trapped in the metastable $\gamma$ phase and a newer type of metastable " $X$ " phase which has high solubility for titanium, as reported in the literature, did not form in any of the processes studied. The imposed rapid solidification condition had caused all the phases stabilized to be of nanocrystalline sizes which could be verified by Hall-Williamson analysis. Owing to the solute trapping of titanium the lattice of metastable $\gamma$ phase was severely micro strained and titanium cation was nearly insoluble in $\alpha$ phase.

Oliker et al. [27] studied the Formation of detonation coatings based on titanium aluminide alloys and aluminium titanate ceramic sprayed from mechanically alloyed powders $\mathrm{Ti}-\mathrm{Al}$.The powders were prepared by milling of TiAl $(\gamma)$ ingot and mechanical alloying of the Ti and Al elementary powders. The application of the nanocomposite powder materials which were activated by the mechanical alloying made the phase formation process in the coatings more universal and adjustable due to more active and sensitive response of powder material to a gas environment. Authors presented that from the mechanically alloyed powder Ti-50Al, it is possible to consolidate by the detonation spraying method the ceramic coating based on the compound $\mathrm{Al}_{2} \mathrm{TiO}_{5}$ at oxidizing influence of the working gas environment on the powder. Coating based on the titanium aluminides with inclusions TiN can be formed at nitriding influence of the working gas environment on the powder. At the use of the cast microsize powder $\operatorname{TiAl}(\gamma)$, its phase composition is inherited by the coating.

Rajasekaran et al. [28] studied the effect of detonation gun sprayed $\mathrm{Cu}-\mathrm{Ni}$-In coating on plain fatigue and fretting fatigue behaviour of Al-Mg-Si alloy. Coated samples were characterized with reference to the microstructure, porosity, residual stresses, microhardness and surface roughness. Plain fatigue (without fretting) and fretting fatigue tests were carried out at room temperature on uncoated and coated specimens. The detonation gun spray process resulted in a dense coating of almost uniform deposition with low porosity (0.3\%) and good adhesion between the substrate and the coating. Under plain fatigue loading $40 \mu \mathrm{m}$ thick coated samples exhibited superior lives compared with uncoated and $100 \mu \mathrm{m}$ thick coated specimens due to the presence of higher surface compressive residual stress in the former. Delamination-induced failure resulted in inferior lives of $100 \mu \mathrm{m}$ thick coated specimens. Under fretting fatigue deformation $40 \mu \mathrm{m}$ thick coated specimens exhibited superior lives compared with $100 \mu \mathrm{m}$ thick coated samples owing to higher compressive residual stress at the surface and better interfacial adhesion. At $120 \mathrm{MPa}$ stress level $40 \mu \mathrm{m}$ thick coated specimens exhibited superior fretting fatigue life compared with uncoated sample and at stress levels above $120 \mathrm{MPa}$ the converse was true. This was attributed to interface cracking at higher stress levels. 
Murthy et al. [29] analyzed the abrasive wear behaviour of $\mathrm{WC}-\mathrm{CoCr}$ and $\mathrm{Cr}_{3} \mathrm{C}_{2}-20(\mathrm{NiCr})$ deposited by HVOF and detonation spray processes. The abrasion tests were done using a threebody solid particle rubber wheel test rig using silica grits as the abrasive medium. Authors found that the DS coating performs slightly better than the HVOF coating possibly due to the higher residual compressive stresses induced by the former process and WC-based coating has higher wear resistance in comparison to $\mathrm{Cr}_{3} \mathrm{C}_{2}$-based coating. Also, the thermally sprayed carbidebased coatings have excellent wear resistance with respect to the hard chrome coatings.

Ke et al. [30] studied the thermal barrier coatings deposited by detonation gun spraying on a Nibase superalloy, M38G. The thermal conductivity of freestanding YSZ coatings and the thermal shock behaviors of TBCs system were studied. The results showed that the D-gun sprayed TBC had a very low thermal conductivity of 1.0-1.4 W/m K, close to that of the plasma sprayed YSZ coatings and much lower than their EB-PVD counterparts. The TBCs exhibited excellent resistance to thermal shock up to 400 cycles of $1050{ }^{\circ} \mathrm{C}$ to room temperature (forced air cooling) +200 cycles of $1100{ }^{\circ} \mathrm{C}$ to room temperature (forced water quenching). Authors discussed the damage evolution mode of TBC system during the thermal cycling in the light of the features of microstructural development and phase changes.

Influence of process variables on the qualities of detonation gun sprayed WC-Co coatings was analyzed by $\mathrm{Du}$ et al. [31]. Experimental results were presented in terms of the structure, including surface roughness, XRD patterns and porosity, as well as adhesion strength, hardness, and fracture toughness of D-gun-sprayed WC-Co coatings as a function of spraying distance from nozzle exit to substrate and ratio of $\mathrm{O}_{2}: \mathrm{C}_{2} \mathrm{H}_{2}$. Authors found that both the spraying parameters influence structure and properties of D-gun-sprayed WC-Co coatings. The decarburization of WC-Co powders during the spraying was little even when the highest oxygen-fuel ratio was employed. When the higher oxygen-fuel ratio was employed, hardness and adhesion increase, while, porosity and fracture toughness decrease, which can be attributed to the higher temperature and velocity feed powders obtained from the detonation wave. On the other hand, denser microstructure, higher adhesion strength and higher hardness appear when the coating was deposited at spraying distance of $110-20 \mathrm{~mm}$, while fracture toughness is a little lower, which may come from the best compromise of decreasing velocity and lagging of heat transfer process for the particles to obtain a good molten state.

Sundararajan et al. [32] studied about the importance of process parameters on the tribological behaviour of detonation sprayed coatings. The tribological performance of thermal spray coatings depends on a host of properties like coating composition, nature of phases and their distribution, microstructure, porosity and residual stress. All these properties, in turn, determine the hardness of the coating, which is conventionally used as the primary correlating parameter for evaluating wear resistance. To assess such an interrelationship in the case of detonation sprayed coatings, large varieties of coatings and each coating over a range of process parameters 
were deposited utilizing the detonation spray (DS) coating technique. The resulting coatings (94 in all) have been characterized in terms of phase content and distribution, porosity, microhardness, and evaluated for erosion, abrasion and sliding wear resistance Analysis of the data obtained clearly points to the fact that the coatings are substantially poorer than bulk material of identical composition and that the hardness and tribological properties of the coatings are more strongly influenced by the coating process parameters themselves rather than microstructural parameters like phase content and distribution, porosity, etc.

Reaction of $\mathrm{ZrO}_{2}-\mathrm{CaO}-\mathrm{ZrSiO}_{4}$ and $\mathrm{ZrO}_{2}-\mathrm{Y}_{2} \mathrm{O}_{3}-\mathrm{ZrSiO}_{4}$ detonation thermal sprayed coatings with manganese oxide at $1273 \mathrm{~K}$ was investigated by Gao [33]. Phase transformations and the reaction of $\mathrm{ZrO}_{2}-\mathrm{CaO}-\mathrm{ZrSiO}_{4}$ and/or $\mathrm{ZrO}_{2}-\mathrm{Y}_{2} \mathrm{O}_{3}-\mathrm{ZrSiO}_{4}$ coatings with manganese oxide at $1273 \mathrm{~K}$ were investigated using X-ray diffraction (XRD) and scanning electron microscopy (SEM). $\mathrm{SiO}_{2}$ phase formed in the coatings, mainly due to the decomposition of $\mathrm{ZrSiO}_{4} \cdot \mathrm{SiO}_{2}$ reacts easily with manganese oxide or calcium oxide. The reaction between $\mathrm{SiO}_{2}$ and $\mathrm{MnO}$ primary occurred in the $\mathrm{ZrO}_{2}-\mathrm{Y}_{2} \mathrm{O}_{3}-\mathrm{ZrSiO}_{4}$ coatings and result in the damage or exfoliation on the surface of a coating.

Wu et al. [34] studied the high temperature properties of thermal barrier coatings obtained by detonation spraying. NiCrAlY/YPSZ and NiCrAlY/NiAl/YPSZ thermal barrier coatings (TBCs) were successfully deposited by detonation spraying. The results indicated that the detonation sprayed TBCs included a uniform ceramic coat containing a few microcracks and a bond coat with a rough surface. The lamellar structure and the presence of cracks and impurities could reduce the thermal conductivity of the ceramic coat. Oxidation kinetics at $1000-1150{ }^{\circ} \mathrm{C}$ of detonation sprayed TBCs have been measured and discussed by authors. The role of a $\mathrm{Ni}-\mathrm{Al}$ intermediate layer in improving the oxidation resistance of duplex TBCs has also been studied. Oxidation behavior of such coatings was also studied by Y. N. Wu et al. [35]. The oxidation behaviors of detonation sprayed TBCs at 1000 and $1100{ }^{\circ} \mathrm{C}$ were studied. The results indicated that the detonation sprayed TBCs were uniform and dense, with a few microcracks in the ceramic coats and a rough surface of bond coats. At the high temperature, the dense detonation sprayed ceramic coats with low porosity could obviously decrease the diffusive channels for oxygen and reduce the oxygen pressure $\left(\mathrm{PO}_{2}\right)$ at the ceramic/bond coat interface. Under the lower oxygen pressure at the interface, it was advantageous to the formation of a continuous protective $\mathrm{Al}_{2} \mathrm{O}_{3}$ layer and the growth of a thermally grown oxide layer (TGO) obeyed the fourth power law.

Evaluation of functionally graded thermal barrier coatings fabricated by detonation gun spray technique was done by Kim et al. [36]. FGM TBCs were sprayed in the form of multi-layered coatings with a compositional gradient along the thickness direction. The gradient ranged from $100 \%$ NiCrAlY metal on the substrate to a $100 \% \mathrm{ZrO}_{2}-8$ wt. $\% \mathrm{Y}_{2} \mathrm{O}_{3}$ ceramic for the topcoat, and consisted of a finely mixed microstructure of metals and ceramics with no obvious interfaces 
between the layers. In the FGM layer of the FGM TBCs, the ceramics and metals maintained their individual properties without any phase transformation during the spraying process. Thermal shock properties of FGM TBCs were also investigated and the data obtained were compared with those for traditional duplex TBCs.

Cetegen et al. [37] studied the deposition of multilayered alumina-titania coatings by detonation waves. Multi-layered alumina-titania coatings were formed from conventional and nanostructured powders by detonation technique. Alternate layers of the developed coatings contain partially melted nano-structured material. Authors evaluated that microhardness across the coating thickness exhibits high and low values for the conventional and the nano-structured layers respectively.

Zhang et al. [38] investigated $1050^{\circ} \mathrm{C}$ isothermal oxidation behavior of detonation gun sprayed NiCrAlY coating. NiCrAlY coating was deposited on a single crystal Ni-base superalloy by detonation gun spraying. By means of XRD, SEM and EDS, isothermal oxidation behavior of the coatings at $1050{ }^{\circ} \mathrm{C}$ were studied. The results showed that detonation gun sprayed NiCrAlY coatings held a favorable oxidation resistance. Their oxidation kinetics at $1050{ }^{\circ} \mathrm{C}$ obeyed the parabolic law. $\alpha-\mathrm{Al}_{2} \mathrm{O}_{3}$ scale was formed on the coating surface and kept almost intact after oxidation for $300 \mathrm{~h}$. Internal oxidation led to the formation of $\mathrm{Al}_{2} \mathrm{O}_{3}$ at the coating/substrate interface, and needlelike ( $\mathrm{Al}, \mathrm{N}$ ) compounds appeared in the undersurface area of the substrate.

Semenov and Cetegen [39] studied the deposition of nano-structured alumina-titania coatings by detonation waves. Experiments involved entrainment of conventional (Metco 130) and nanostructured/agglomerated alumina-titania powders with particle size distributions between 10 and $120 \mu \mathrm{m}$ into the convective flow behind detonation waves. A stoichiometric mixture of acetylene-oxygen was utilized in these experiments. Small quantities of powder (0.8-1.2 g) were placed in the detonation tube at fixed distances from the deposition location. The variation of the initial powder location along the detonation tube allowed different residence times of particles in the flow before deposition, thus allowing variation of the thermal and kinetic states of the particles prior to deposition. Authors presented result in terms of the microstructure of the deposited coatings and coating micro-hardness. The coating characterization was performed as a function of the initial powder location. It was found that the cross-sections of the coatings contained significant regions with feature sizes of several hundred nanometers. Due to the low temperatures and high velocities attained by particles in the detonation process, coating structure is quite different than those obtained in plasma deposition. Results from modeling of particle motion and heat-up suggest that different size powder particles are accelerated and heated-up at different rates in the detonation process. Small particles are more rapidly accelerated and reach higher temperatures as compared to the larger sizes. This leads to upper layers of the coatings having the larger particles that may have very little or no melting versus lower layers of the coating consisting of small particles that undergo significant melting. Authors found the un- 
melted portions containing significant nano-structure from the feedstock material to be mostly responsible for the retained nano-structure. Coating micro-hardness was found to increase with the increasing stand-off distance between the initial powder location and the deposition point. For each sample, higher hardness values were found in the lower layers of the coating consisting of melted regions. Metco 130 detonation coatings exhibited a stronger dependence of microhardness on the stand-off distance between the initial powder and the deposition location as compared to the nano-structured powder. Detonation coatings generated from nano-structured powder have consistently 30-60\% higher micro-hardness values above those for typical plasma coatings utilizing the same material.

Effect of grinding on the erosion behavior of a WC-Co-Cr coating deposited by HVOF and detonation gun spray process was investigated by Murthy et al. [40]. Comparison has also been brought out between two high velocity coating processes namely high velocity oxy-fuel (HVOF) and detonation gun spray process (DS). A WC-10Co-4Cr powder was sprayed on a medium carbon steel using the above mentioned high velocity spray processes. Some of the coated specimens were further ground by a diamond wheel with controlled parameters. The coating in both 'as-coated' and 'as-ground' conditions has been tested for solid particle erosion behaviour. The erosion experiments were carried out using an air-jet erosion test rig with silica erodents at a velocity of $80 \mathrm{~m} / \mathrm{s}$. It has been found that surface grinding improved the erosion resistance. Authors presented detailed characterisation of the WC-Co-Cr coating in both 'as-coated' and 'as-ground' form. A detailed analysis indicated that the increase in residual stress in the ground specimen is a possible cause for the improvement in erosion resistance.

Saravanan et al. [41] studied the influence of process variables on the quality of detonation gun sprayed alumina coatings. The Coating experiments were conducted, using a Taguchi-full factorial (L16) design parametric study, to optimize the D-gun spray process parameters. Four selected important spraying parameters were considered in their upper and lower levels of the predefined range according to the test matrix, in order to display the range of processing conditions and their effect on the coating quality. Optical microscopy, scanning electron microscopy, X-ray diffraction, image analysis and hardness testing was used for characterization. Coating qualities are discussed with respect to surface roughness, hardness, porosity and microstructure. The attributes of the coatings are correlated with the changes in operating parameters and their relative importance and contribution ratios to overall variance are calculated.

Wang et al. [42] studied the $\mathrm{Cr}_{3} \mathrm{C}_{2}-\mathrm{NiCr}$ detonation spray coating. The detonation spray coating was used to try and protect the conticaster rolls. Using the orthogonal test, suitable technological parameters were obtained. Authors found that the coatings processed were dense with good bonding to substrate as well as high resistance to high temperature oxidation and wear. Reports 
from the in-service test at Bao Shan Steel Company indicated that the $\mathrm{Cr}_{3} \mathrm{C}_{2}-\mathrm{NiCr}$ detonation spray coating produced by authors has at least doubled the roll life.

Direct morphological comparison of vaccum plasma sprayed and detonation gun sprayed hydroxyapatite coatings for orthopaedic applications was done by Gledhill et al. [43]. Hydroxyapatite coatings on titanium substrates were produced using two thermal spray techniques_-vacuum plasma spraying and detonation gun spraying. X-ray diffraction was used to compare crystallinity and residual stresses in the coatings. Porosity was measured using optical microscopy in conjunction with an image analysis system. Scanning electron microscopy and surface roughness measurements were used to characterise the surface morphologies of the coatings. The vacuum plasma sprayed coatings were found to have a lower residual stress, a higher crystallinity and a higher level of porosity than the detonation gun coatings. Authors concluded that consideration needs to be given to the significance of such variations within the clinical context.

A research on detonation gun coating with Fe-SiC composite powders mechanically activated was done by Jia et al. [44]. The Fe-SiC composite powder prepared by the mechanical activation process has been used for coating on materials with the detonation gun (D-gun) machine in order to develop a new way for coating. Authors found that the coating layer has fine, homogeneous, dense structure and good wear resistance. The results of SEM and X-ray diffraction (XRD) show that some reactions happened between $\mathrm{Fe}$ and $\mathrm{SiC}$ during the D-gun coating, the Fe-Si compounds formed and $\mathrm{SiC}$ strength the coating layer. It was proved that the technology combined mechanical alloying with D-gun coating is a new method for surface modification.

Multilayer coating by continuous detonation system spray technique was studied by Fagoaga et al. [45]. A multilayer coating of chromium oxide/chromium carbide for erosion-corrosion protection of furnace boiler-walls was produced by thermal spray continuous detonation system (CDS) technique. These composite coatings presented a microstructure made by alternate phases of chromium carbide cermet and oxides resulting from preferential oxidation of chromium compounds. Authors discussed the mechanisms for the generation of such mixed structure. Produced coatings were characterized by electron probe microanalysis, X-ray diffraction and ultramicrohardness techniques, combined with traditional procedures of metallographic preparation, quantitative image analysis, and microhardness testing.

Ahmed and Hadfield [46] investigated the rolling contact fatigue performance of detonation gun coated elements. A modified four ball machine which simulates a rolling element bearing was used to examine the coating performance and failure modes in a conventional steel ball bearing and hybrid ceramic bearing configurations. Tungsten carbide (WC-15\% Co) and aluminium oxide $\left(\mathrm{Al}_{2} \mathrm{O}_{3}\right)$ were thermally sprayed using a super D-Gun (SDG2040) on M-50 bearing steel substrate in the geometrical shape of a cone. A coated cone replaced the upper ball that contacts with three lower balls. The rolling contact fatigue (RCF) tests were performed under immersed 
lubricated conditions using two different lubricants. Fatigue failure modes were observed using a scanning electron microscope. Microhardness measurements of the coating and the substrate and elastohydrodynamic fluid film thickness results are included. Authors found the requirement for significant optimization of the coating before use in rolling element bearing applications. The coating was fractured in a delamination mode. Authors found that an optimization in coating process is required before these coatings can be used for rolling contact applications. WC-Co coatings performed better than $\mathrm{Al}_{2} \mathrm{O}_{3}$ coatings in rolling contact.

Wood et al. [47] studied the sand erosion performance of detonation gun applied tungsten carbide/cobalt-chromium coatings. Study was undertaken using a sand/water jet impingement rig. Authors found that the erosion rate of sprayed compared to sintered tungsten carbide-cobaltchrome was similar for low energy impacts but the sintered material outperforms by 4 times the sprayed material for high energy impacts. This reflects the anisotropic microstructure of the thermally sprayed coating with preferred crack propagation parallel to the coating surface followed by crack interlinking and spalling. This is the dominant erosion mechanism present. A minor erosion mechanism consists of micro-cutting and ploughing at low angles of particle impact. The coatings have a relatively high density of defects including thermal stress induced transverse cracks, voids, oxides, and grit blasting remnants. Such defects were shown which accelerate the erosion process considerably because they aid crack initiation and growth leading to partial, mono or multi-splat spalling of loose material. The influence of slurry jet angle was found to be more pronounced under low energy conditions where maximum erosion occurred at $90^{\circ}$ and the minimum at $30^{\circ}$ in contrast to the high energy erosion rates which were independent of jet angle. Authors found that this was due to the lower levels of fluctuating stresses imparted to the coating during low energy impacts leading to the impact angle having a greater effect on sub critical growth rate than for the high energy conditions.

$\mathrm{Li}$ and Ohmori [48] examined the lamellar structure of a detonation gun sprayed $\mathrm{Al}_{2} \mathrm{O}_{3}$ coating. The structural features of a detonation gun sprayed $\mathrm{Al}_{2} \mathrm{O}_{3}$ coating was examined using a copper electroplating technique. Authors revealed that the detonation gun sprayed $\mathrm{Al}_{2} \mathrm{O}_{3}$ coating has a typical layer structure similar to that of coatings deposited using other thermal spraying processes. Despite having the highest particle velocity of the thermal spraying processes, lamellar bonding at the interfaces between flattened particles in detonation gun sprayed $\mathrm{Al}_{2} \mathrm{O}_{3}$ coatings was very poor. The mean bonding ratio of bonded interface area to apparent bonding interface for a typical detonation gun $\mathrm{Al}_{2} \mathrm{O}_{3}$ coating is about $10 \%$, which is less than one-third the value for a typical plasma-sprayed $\mathrm{Al}_{2} \mathrm{O}_{3}$ coating. However, the high particle velocity results in the formation of a rough surface on the spray splat, which may be effective in enhancing interlocking between flattened particles.

Detonation gun-sprayed cermet coatings containing complex ternary transition metal borides as hard particles dispersed in a stainless steel or nickel-based superalloy matrix have been 
characterized by Keranen et al.[49] to ascertain the effects of crystallinity and distribution of hard particles on the wear properties. Optical microscopy, scanning electron microscopy (SEM), $\mathrm{X}$-ray diffraction (XRD) and analytical transmission electron microscopy (AEM) were used for characterization. Moreover, abrasive wear resistance of coatings was evaluated with a rubber wheel abrasion testing system.

The wear and friction behaviors of detonation-gun- (D-gun) and plasma-sprayed hard coatings were investigated by Yinglong [50] under dry sliding conditions. The coating materials studied included $\mathrm{Cr}_{2} \mathrm{O}_{3}$, WC-12\%Co, WC-20\%Co, $\mathrm{Al}_{2} \mathrm{O}_{3}, \mathrm{TiO}_{2}, \mathrm{Al}_{2} \mathrm{O}_{3}-40 \% \mathrm{TiO}_{2}, \mathrm{TiC}-20 \% \mathrm{Ni}$ and $\mathrm{Cr}_{3} \mathrm{C}_{2}-25 \% \mathrm{NiCr}$. Sintered WC-6\%Co and steel MoCN315M were also investigated as references. Scanning electron microscopy analysis was carried out to study the wear mechanisms. Authors found that D-gun-sprayed hard coatings had higher hardness, density and wear resistance than the corresponding plasma-sprayed coatings. D-gun-sprayed $\mathrm{Cr}_{2} \mathrm{O}_{3}$ showed the highest wear resistance. The wear resistance of D-gun-sprayed $\mathrm{Cr}_{2} \mathrm{O}_{3}$ was even higher than that of sintered WC-6\%Co.

Ningkang et al. [51] studied the electron beam treatment of detonation-sprayed Stellite coatings. After detailed microstructural and microchemical studies of the coatings authors found that the degree of enhancement of chemical homogeneity in the coatings, the elimination of porosity and impurities, and the development of metallurgical bonding at the coating-substrate interface with consequent improvement in coating adhesion were all dependent on the selection of the electron beam processing parameters.

\section{CONCLUSION}

Detonation sprayed coatings can play important role in protecting materials and alloys from wear and corrosion phenomena.

Work has been done by various researchers to investigate the performance of detonation sprayed coatings. However more research is needed to evaluate the performance of detonation sprayed coatings in actual environment. Process parameters of detonation spraying influence the microstructure, mechanical and other properties of the coatings. Research is needed in optimization of the process parameters of detonation spraying process. Detonation gun separation device designed by researchers resulted in good performance of the detonation gun spraying in high performance requirement. More improvement can be done in the design of detonation gun spraying device. Little work is done in field of using nano structured powder with detonation spraying. More work is needed in using of nanostructured powder for coating by detonation spraying for wear and corrosion resistance.

\section{REFERENCES}


[1] Chawla Vikas, Sidhu Buta Singh, Puri D. and Prakash S.; “performance of plasma sprayed Nanostructured and Conventional Coatings”, Journal of the Australian Ceramic Society, Volume 44, Number 2, (2008), 56-62.

[2] Sidhu Buta Singh, Puri D., Prakash S.; "Mechanical and metallurgical properties of plasma sprayed and laser remelted Ni-20Cr and Stellite-6 coatings”, Journal of Materials Processing Technology”, Volume 159, (2005), 347-355.

[3] Goyal Rakesh, Sidhu Buta Singh, Grewal J.S.; "Surface Engineering and Detonation Gun Spray Coating”, International Journal of Engineering Studies, Volume 2, Number 3 (2010), 351-357.

[4] Rajasekaran B., Sundara Raman Ganesh S., Joshi S.V., Sundararajan G.; "Influence of detonation gun sprayed alumina coating on AA 6063 samples under cyclic loading with and without fretting”, Tribology International, Volume 41, (2008), 315-322.

[5] Souza V.A.D., Neville A.; "Aspects of microstructure on the synergy and overall material loss of thermal spray coatings in erosion-corrosion environments”, Wear, Volume 263, (2007), 339-346.

[6] Sova, Pervushin D., Smurov I.; "Development of multimaterial coatings by cold spray and gas detonation spraying”, Surface and coatings technology, Volume 205, Number 4, (2010), 1108-1114.

[7] Wang Tie-Gang, Zhao Sheng-Sheng, Hua Wei-Gang, Li Jia-Bao, Gong Jun, Sun Chao; "Estimation of residual stress and its effects on the mechanical properties of detonation gun sprayed WC-Co coatings”, Materials Science and Engineering: A, Volume 527, Number 3, 454-461.

[8] Sundarajan G., Sivakumar G., Sen D., Rao Srinivasa D., Ravichandra G.; “The tribological behaviour of detonation sprayed TiMo(CN) based cermet coatings", International journal of refractory metals and hard materials, Volume 28, Number 1, (2010), 71-81.

[9] Kamal Subash, Jayaganthan R., Prakash Satya; “ Mechanical and microstructural characteristics of detonation gun sprayed NiCrAlY+ 0.4 wt\% $\mathrm{CeO}_{2}$ coatings on superalloys”, Materials chemistry and physics, Volume 122, Number 1, (2010), 262-268.

[10] Senderowski C., Bojar Z., Wolczynski W., Pawlowski A.; "Microctructure characterization of D-gun sprayed Fe-Al intermetallic coatings”, Intermetallics, Volume 18, Number 7, 1405-1409.

[11] Wang Tie-Gang, Zhao Sheng-Sheng, Hua Wei-Gang, Gong Jun, Sun Chao; “ Design of separation device used in detonation gun spraying system and its effects on the performance of WC-Co coatings”, Surface and Coatings Technology, Volume 203, Number 12, (2009), 1637-1644.

[12] ZHOU Zheng, WANG Lu, WANG Fu-chi, LIU Yan-bo; "Formation and corrosion behavior of Fe-based amorphous metallic coatings prepared by detonation gun spraying”, Transactions of nonferrous metals society of china, Volume 19, Number 3, (2009), 634638. 
[13] Rajasekaran B., Sundara Raman Ganesh S., Joshi S.V., Sundarajan G.; “ Effect of grinding on plain fatigue and fretting behaviour of detonation gun sprayed Cu-Ni-ln coating on Al-Mg-Si alloy”, International journal of fatigue, Volume 31, Number 4, (2009), 791-796.

[14] Kamal Subash, Jayaganthan R., Prakash S.; "High temperature oxidation studies of detonation sprayed $\mathrm{Cr}_{3} \mathrm{C}_{2}-\mathrm{NiCr}$ coating on Fe- and Ni-based superalloys on air under cyclic condition at $900^{\circ} \mathrm{C}$, Journal of alloys and compounds, Volume 472, Number 1-2, (2009), 378-389.

[15] Kamal Subash, Jayaganthan R., Prakash Satya; “ Evaluation of cyclic hot corrosion behaviour of detonation gun sprayed $\mathrm{Cr}_{3} \mathrm{C}_{2}-25 \% \mathrm{NiCr}$ coatings on nickel- and iron- based superalloys”, Surface and coatings technology, Volume 203, Number 8, (2009), 10041013.

[16] Zhu JingLei, JiHua, Wang HaiTao, Xu JunLong, Zhao XingKe, Zhang Hua; “In-situ synthesis and microstructure of TiC-Fe36Ni composite coatings by reactive detonation gun spraying”, Materials letters, Volume 62, Number 12-13, (2008), 2009-2012.

[17] Senderowski Cezary, Bojar Zbigniew; "Gas detonation spray forming of Fe-Al coatings in the presence of interlayer”, Surface and coatings technology, Volume 202, Number 15, (2008), 3538-3548.

[18] Rajasekaran B., Sundara Raman Ganesh S., Joshi S.V., Sundarajan G.; "Performance of plasma sprayed and detonation gun sprayed Cu-Ni-ln coatings on Ti-6Al-4V under plain fatigue and fretting fatigue loading”, Materials science and engineering: A, Volume 479, Number 1-2, (2008), 83-92.

[19] Yuan F.H., Chen Z.X., Huang Z.H., Wang Z.G, Zhu S.J.; “ Oxidation behavior of thermal barrier coatings with HVOF and detonation sprayed NiCrAlY bondcoats”, Corrosion science, Volume 50, Number 6, (2008), 1608-1617.

[20] Rajasekaran B., Sundara Raman Ganesh S., Joshi S.V., Sundarajan G.; “ Influence of detonation gun sprayed alumina coating on AA6063 samples under cyclic loading with and without fretting”, Tribology international, Volume 41, Number 4, (2008), 315-322.

[21] Kamal Subhash, Jayaganthan R., Prakash S., Kumar Sanjay; “ Hot corrosion behavior of detonation gun sprayed $\mathrm{Cr}_{3} \mathrm{C}_{2}$-NiCr coatings on $\mathrm{Ni}$ and Fe-based superalloys in $\mathrm{Na}_{2} \mathrm{So}_{4}$ $60 \% \mathrm{~V}_{2} \mathrm{O}_{5}$ environment at $900^{\circ} \mathrm{C}$, Journal of alloys and compounds, Volume 463, Number 1-2, (2008), 358-372.

[22] Babu Suresh P., Basu Bikramjit, Sundararajan G.; "Processing-structure-property correlation and decarburization phenomenon in detonation sprayed WC-12CO coatings", Acta materialia, Volume 56, Number 18, (2008), 5012-5026.

[23] Park S.Y., Kim M.C., Park C.G.; "Mechanical properties and microstructure evolution of the nano WC-Co coatings fabricated by detonation gun spraying with post heat treatment”, Material science and engineering: A, Volume 449-451, (2007), 894-897.

[24] Du Hao, Sun Chao, Hua Weigang, Wang Tiegang, Gong Jun, Jiang Xin, Lee Soo Wohn; "Structure, mechanical and sliding wear properties of $\mathrm{WC}-\mathrm{Co} / \mathrm{MoS}_{2}-\mathrm{Ni}$ coatings by 
detonation gun spray”, Materials science and engineering: A, Volume 445-446, (2007), 122-134.

[25] Murthy J.K.N., Bysakh S., Gopinath K., Venkataraman B.; “ Microstructure dependent erosion in $\mathrm{Cr}_{3} \mathrm{C}_{2}-20(\mathrm{NiCr})$ coating deposited by detonation gun”, Surface and coatings technology, Volume 202, Number 1, (2007), 1-12.

[26] Venkataraman R., Ravikumar B., Krishnamurthy R., Das D.K.; “ A study on phase stability observed in as sprayed Alumina-13 wt.\% Titania coatings grown by detonation gun and plasma spraying on low alloy steel substrates”, Surface and Coatings Technology, Volume 201, Number 6, (2006), 3087-3095.

[27] Oliker V.E., Sirovatka V.L., Timofeeva I.I., Gridasova T.Ya., Hrechyshkin Ye.F.; “ Formation of detonation coatings based on titanium aluminide alloys and aluminium titanate ceramic sprayed from mechanical alloyed powders Ti-Al”, Surface and Coatings Technology, Volume 200, Number 11, (2006), 3573-3581.

[28] Rajasekaran B., Sundara Raman Ganesh S., Joshi S.V., Sundararajan G.; “ Effect of detonation gun sprayed $\mathrm{Cu}-\mathrm{Ni}$-ln coating on plain fatigue and fretting fatigue behaviour of Al-Mg-Si alloy”, Surface and Coatings Technology, Volume 201, Number 3-4, (2006), 1548-1558.

[29] Murthy J.K.N., Venkataraman B.; “Abrasive wear behavior of WC-CoCr and $\mathrm{Cr}_{3} \mathrm{C}_{2}$ 20(NiCr) deposited by HVOF and detonation spray processes”, Surface and Coatings Technology, Volume 200, Number 8, (2006), 2642-2652.

[30] Ke P.L., Wu Y.N., Wang Q.M., Gong J., Sun C., Wen L.S.; "Study of thermal barrier coatings deposited by detonation gun spraying”, Surface and Coatings Technology, Volume 200, Number 7, (2005), 2271-2276.

[31] Du Hao, Hua Weigang, Liu Jiangang, Gong Jun, Sun Chao, Wen Lishi; "Influence of process variables on the qualities of detonation gun sprayed WC-Co coatings”, Materials Science and Engineering: A, Volume 408, Number 1-2, (2005), 202-210.

[32] Sundararajan G., Sen D., Sivakumar G.; "The tribological behavior of detonation sprayed coatings: the importance of coating process parameters”, Wear, Volume 258, Number 14, (2005), 377-391.

[33] Yang Gao; "Reaction of $\mathrm{ZrO}_{2}-\mathrm{CaO}-\mathrm{ZrSiO}_{4}$ and $\mathrm{ZrO}_{2}-\mathrm{Y}_{2} \mathrm{O}_{3}-\mathrm{ZrSiO}_{4}$ detonation thermal sprayed coatings with manganese oxide at 1273K”, Surface and Coatings Technology, Volume 195, Number 2-3, (2005), 320-324.

[34] Wu Y.N., Ke P.L., Wang Q.M., Sun C., Wang F.H.; “ High temperature properties of thermal barrier coatings obtained by detonation spraying”, Corrosion Science, Volume 46, Number 12, (2004), 2925-2935.

[35] Wu Y.N., Wang F.H., Hua W.G., Gong J., Sun C., Wen L.S.; “Oxidation behavior of thermal barrier coatings obtained by detonation spraying”, Suraface and Coatings Technology, Volume 166, Number 2-3, (2003), 189-194. 
[36] Kim J.h., Kim M.C., Park C.G.; "Evaluation of functionally graded thermal barrier coatings fabricated by detonation gun spray technique”, Surface and Coatings Technology, Volume 168, Number 2-3, (2003), 275-280.

[37] Cetegen Baki M., Semenov Sergey Y., Goberman Daniel; "Deposition of multi-layered alumina-titania coatings by detonation waves”, Scripta Materialia, Volume 48, Number 10, (2003), 1483-1488.

[38] Zhang Yu-Juan, Sun Xiao-Feng, Guan Heng-Rong, Hu Zhuang-Qi; “ $1050^{0} \mathrm{C}$ isothermal oxidation behavior of detonation gun sprayed NiCrAlY coating”, Surface and Coatings Technology, Volume 161, Number 2-3, (2002), 302-305.

[39] Semenov Sergey Y., Cetegen Baki M.; "Experiments and modeling of the deposition of nano-sttructured alumina-titania coatings by detonation waves”, Materials Science And Engineering A, Volume 335, Number 1-2, (2002), 67-81.

[40] Murthy J.K.N., Rao D.S., Venkataraman B.; "Effect of grinding on the erosion behavior of WC-Co-Cr coating deposited by HVOF and detonation gun spray processes”, Wear, Volume 249, Number 7, (2001), 592-600.

[41] Saravanan P., Selvarajan V., Rao D.S., Joshi S.V., Sundararajan G.; "Influence of process variables on quality of detonation gun sprayed alumina coatings”, Surface and Coatings Technology, Volume 123, Number 1, (2000), 44-54.

[42] Wang Jun, Zhang Li, Sun Baode, Zhou Yaohe; “ Study of the $\mathrm{Cr}_{3} \mathrm{C}_{2}-\mathrm{NiCr}$ detonation spray coating”, Surface and Coatings Technology, Volume 130, Number 1, (2000), 6973.

[43] Gledhill H.C., Turner I.G., Doyle C.; "Direct morphological comparison of vacuum plasma sprayed and detonation gun sprayed hydroxypatite coatings for orthopaedic applications”, Biomaterials, Volume 20, Number 4, (1999), 315-322.

[44] Jia Chengchang, Li Zhicong, Xie Zizhang; “ A research on detonation gun coating with Fe-SiC composite powders mechanically activated”, Materials Science and Engineering A, Volume 263, Number 1, (1999), 96-100.

[45] Fagoaga I., Viviente J.L., Gavin P., Bronte J.M., Garcia J., Tagle J.A.; “Multilayer coatings by continous detonation system spray technique”, Thin Solid Films, Volume 317, Number 1-2, (1998), 259-265.

[46] Ahmed R., Hadfield M.; "Rolling contact fatigue performance of detonation gun coated elements”, Tribology International, Volume 30, Number 2, (1997), 129-137.

[47] Wood R.J.K., Mellor B.G., Binfield M.L.; “Sand erosion performance of detonation gun applied tungsten carbide/cobalt-chromium coatings”, Wear, Volume 211, Number 1, (1997), 70-83.

[48] Li Chang-Jiu, Ohmori Akira; “ The lamellar structure of detonation gun sprayed $\mathrm{Al}_{2} \mathrm{O}_{3}$ coating”, Surface and Coatings Technology, Volume 82, Number 3, (1996), 254-258.

[49] Keranen J., Stenberg T., Mantyla T., Lepisto T.; "Microstructural characterization of detonation gun sprayed boride-based cermet coatings”, Surface and Coatings Technology, Volume 82, Number 1-2, (1996), 29-37. 
[50] Yinglong Wang; "Friction and wear performances of detonation gun and plasma sprayed ceramic and cermet hard coatings under dry friction”, Wear, Volume 161, Number 1-2, (1993), 69-78.

[51] Ningkang Huang, Yi Wang, Zhong Zhang Xiao, Pu Wang Xiao; "Electron beam treatment of detonation sprayed satellite coatings", Surface and Coatings Technology, Volume 46, Number 3, (1991), 255-263. 